\title{
Framing the pursuit of a physics degree as a hero's journey
}

Gabriel R. Mestas and Hunter G. Close

Department of Physics, Texas State University, 601 University Dr, San Marcos, Texas, 78666

Students today face a reality of ever-increasing chaos. A sense of personal direction can be difficult to attain, especially in the murk of pursuing a degree as rigorous and attention-demanding as physics. Our project aims to frame the pursuit of a physics degree as a hero's journey (Campbell, 1949) in order to design discussion points for undergraduates to consider their experiences from an archetypal view. Our intent is to connect students with timeless and emergent mythological forms that are images of a universal psychology. In this paper, we coordinate stages of the hero's journey with various subjective experiences from undergraduate STEM students, as reported in "Talking About Leaving", (Seymour \& Hewitt, 1997), with supplements from the theory of optimal experience "flow", (Csikszentmihalyi, 1990). Our ultimate goal is to help students understand their experience studying physics in ways that promote productive, responsible, proud, and mentally healthy engagement within their academic and social lives.

2019 PERC Proceedings edited by Cao, Wolf, and Bennett; Peer-reviewed, doi.org/10.1119/perc.2019.pr.Mestas Published by the American Association of Physics Teachers under a Creative Commons Attribution 4.0 license. Further distribution must maintain attribution to the article's authors, cover page, and DOI. 


\section{INTRODUCTION}

\section{A. Motivation for and scope of this study}

This paper's first author (GRM) graduated with a B.S. in physics in 2019. He and second author HGC established an informal mentoring relationship throughout his undergraduate (UG) years, discovered their mutual interest in depth psychology and mythology, and explored applying some themes to the common experiences of UG physics students. GRM's own anecdotal experience was that many peers struggled with structuring their experiences with positive meaning and purpose and could benefit from this framing. In fact, direct engagement of students' models of themselves and their abilities in the face of significant challenges to productively frame failure as an opportunity, and even as necessary, for growth has been shown to develop more adaptive long-term and transferable motivation [1]. Meanwhile, recruitment and retention in physics, and STEM more broadly, clearly remain a national problem [2]. Therefore, we sought to create a framework that could invite student discussion in extra-curricular sessions, led by a mentor, in which themes of common STEM student experiences from research were matched to stages in the hero's journey and to students' individual lives. These sessions have not yet been implemented, nor have any discussion protocols yet been created. Here we lay the groundwork for that future work by explaining the correspondence that we built between elements from each space; these spaces are introduced in Sec. II.

\section{B. TXST physics student demographics}

Texas State University (TXST) is a Hispanic-Serving Institution with a 55\% 6-year graduation rate, of whom $10 \%$ are veterans of the armed forces, and with many first-generation students. Over the quinquennium 2015-2019, TXST averaged $\sim 100$ physics majors enrolled, with $\sim 20$ B.S. physics degrees awarded annually. Of TXST physics students, 35\% are Hispanic, similar to the whole university; $30 \%$ are female, compared with the national average of $20 \%$ [3].

\section{BACKGROUND}

\section{A. The hero's journey}

Joseph Campbell's The Hero with a Thousand Faces [4] is an account of the hero's journey (HJ), which is a metanarrative derived from a large collection of world myths and ritual practices as interpreted through 20th century depth psychology [5]. The HJ reveals the psychological dynamics of the development of the individual from childhood through young-adult competency as they encounter the challenges of life. The motif of the hero describes a universal theme of transformation and adventure, and is commonly represented in terms of a figure who leaves a place of comfort, fears for their own survival, overcomes challenges, discovers hidden abilities and resources, struggles with identity, changes form, achieves an external goal, earns a prize, gains recognition, and returns to help society. We see these themes as plainly applicable to pursuing the typical UG physics degree.

The HJ is sometimes approached with skepticism about its accessibility to all genders. One reason for this is that these traditional myths make heavy symbolic use of gender: e.g., the (often) masculinity of the hero represents agency and independence; feminine figures are often used to represent natural forces, while masculine figures other than the hero often represent social order. This dimension of gender can be disconcerting to those who would work for equal access in our society for people of all genders.

Maureen Murdock interviewed Joseph Campbell in 1981 ([6], p. 2) and was dismayed to hear him explain that "women do not need to make the journey". We do find this report puzzling, considering that (1) many mythological examples in ref. [4] use female protagonists, and (2) Campbell spent the bulk of his career at a women's college. Regardless, Murdock responded by reflecting on her psychotherapeutic experience with women clients and generated The Heroine's Journey [6]. Briefly summarizing: the heroine's journey contains the HJ within itself; however, it also involves the initial separation of the heroine from the world of the feminine, and after the $\mathrm{HJ}$, awakening to and reclaiming aspects of the self that were sacrificed in order to "win" the HJ. Murdock indicates clearly both that the $\mathrm{HJ}$ is for all people, but also all people (not just women) may find it incomplete and may need to grieve and heal its psychological casualties later in life ([6], p. 4). As it happens, author HGC, a man, identifies strongly with these aspects of the Heroine's Journey. We therefore assume the following initial attitudes about the regime of applicability of the HJ: (1) It is an appropriate frame, for essentially all students, for a particular phase of life that is oriented toward stretching one's abilities and achieving a difficult goal, (2) it is not a psychological model for the entire duration of life, and (3) it does not ultimately deny other dimensions of life during the UG years, though it may background them temporarily. It may turn out that students who pursue this heroic path and name it as such will be better off if they see it as a part their current part - and not the whole, of life! This approach accords with feminist critiques of science education, which emphasize considering students' ideas, caring student-teacher relationships, emotional needs, and identity formation [7].

\section{B. Difficulties of pursuing a STEM degree}

Talking About Leaving: Why Undergraduates Leave the Sciences (TAL) [8] presents a three-year study begun in 1990 to dissect primary factors for UG student attrition from STEM to non-STEM fields. This landmark study reports results from over 600 hours of interviews and focus groups with UG 
STEM majors and identifies emergent themes in their subjective experiences. TAL identified (1) sources of qualitative differences in educational experiences of STEM UGs at various institution types, (2) facets of the structure of STEM departments that encourage attrition or impede retention for the entire UG population, and (3) differences in the causes of attrition among students of varying races and genders. ([8], p.14).

TAL is a multi-faceted, detailed source for direct student reflections of their UG STEM experiences; it is therefore well-suited as a proving ground for projecting our understanding of the HJ onto its variety of student experiences and framings. One weakness of this approach leaps out at the outset: TAL mostly reports negative experiences, and neither actual students' experiences nor the stages of the $\mathrm{HJ}$ are that uniformly negative. We therefore supplement the empirical side of our framework with an element from positive psychology: "flow" [9], in which a person engages a high level of challenge with a high level of skill, resulting in strongly positive experience.

We expect that the proposed framework will be appropriate for supporting students from marginalized groups, in addition to those from dominant groups. In a large quantitative study [10] of experiences among STEM majors who were women of color $(\mathrm{N}=1250)$ and white women $(\mathrm{N}=891)$, the most effective retention factors included strong, meaningful connections to peers and a STEM student community, with frequent sharing of ideas and values. Similarly, in a qualitative study [11] of six successful STEM students of color, positive experiences included peer groups that provided encouragement and motivation. The authors recommend ([11], p. 501) that "universities attempt to deconstruct climates of intimidation in which (students feel) their confidence in their abilities is challenged." We envision our HJ sessions as warmly inviting and inclusive, and promoting deep, personal reflection on STEM experiences.

\section{METHOD FOR GENERATING THE FRAMEWORK}

Campbell's The Hero with a Thousand Faces [4] organizes the HJ as a linear sequence of seventeen stages, such as (1) The Call to Adventure, (2) Refusal of the Call, and (3) Supernatural Aid. The linear sequence is not a rigid formula that every myth follows; most myths capture only part of the sequence, or they diverge from it in minor ways. A real human life is usually even less organized, with people feeling that they are in different stages at the same time in different respects ([6], p. 4). Therefore, we studied Campbell's presentation not by mapping it to the chronology of an UG degree, but by reflecting on what psychological experience might be represented by each meta-dramatic stage, how this connected with our own experiences of studying physics, while also connecting with the themes reported by STEM students in TAL and other various results from STEM education research.

When we examined the seventeen stages and the findings in TAL, we found the fit more natural with some HJ stages than with others. Other themes are not necessarily irrelevant and may be understood better in our future work.

TABLE I. Mythological themes from the hero's journey and their correspondence with UG STEM experience as exemplified in Talking About Leaving.

\begin{tabular}{ll}
\hline \hline HJ theme & TAL theme \\
\hline The Call to Adventure & Motivation for choice of major \\
\hline Refusal of the Call & $\begin{array}{l}\text { Difficulty found in } \\
\text { choosing the wrong major }\end{array}$ \\
\hline Supernatural Aid & Assistance from others \\
\hline $\begin{array}{l}\text { The Crossing of the } \\
\text { First Threshold }\end{array}$ & First-year experiences \\
\hline The Belly of The Whale & Under-preparation \\
\hline The Road of Trials & The bulk of the challenges \\
\hline The Ultimate Boon & Competence in one's field \\
\hline Return & Post-Graduate Life \\
\hline \hline
\end{tabular}

\section{STUDENT EXPERIENCES AND MYTHOLOGICAL THEMES}

In this section, we explain seven examples of the correspondence between themes in STEM student experiences from TAL and mythological HJ themes.

\section{A. Choice in a STEM major}

TAL notes 12 common reasons for UG choice in major. Some of them have to do with financial incentives or professional prudence, but others, like "good at math and/or science in high school", "intrinsic interest", or even "uninformed choice" are more like being mysteriously bitten. Campbell relays a story of a princess who is tossing a golden ball, when suddenly the ball rolls into the water and is retrieved by a talking frog. He reflects on the story:

This is an example of one of the ways in which the adventure can begin. A blunder - apparently, the merest chance - reveals an unsuspected world, and the individual is drawn into a relationship with forces that are not rightly understood... The blunder may amount to the opening of a destiny. ([4], p. 45)

Therefore, we map the choice to pursue a STEM major to The Call to Adventure. 


\section{B. Intrinsic interest vs. active influence of others}

Of the 12 reasons for choosing a STEM major, active influence of others (defined by pressure or persuasion of people significant to the students), was the most common reason for choice of major for students who decided to switch out of STEM majors ("switchers"), while intrinsic interest (defined by a motivation from within to study) was the most prevalent reason among "non-switchers". This result is corroborated by more recent research [12], in which interest, performance/competence, and recognition all contribute to one focal construct, physics identity. TAL says "the best foundation for student survival and success is to have chosen one's major because of an intrinsic interest in the discipline and/or in the career fields to which it is leading." ([8], p. 66).

Connecting to mythology, we assign the Refusal of the Call to represent cases in which someone decides not to pursue their passion, and then faces hardships as a result of a lack of passion. One male white mathematics "switcher" reflects:

There was no possibility of taking the time to do some of the classes I enjoyed. Like I couldn't find time for a foreign language. There just wasn't any opportunity for it. You start to realize that you don't want to go on doing this, because it's not exciting enough to allow you to put on blinkers [sic] as far as the rest of the world goes. ([8], p. 60).

Campbell describes the importance of flexible thinking:

The myths and folk tales of the whole world make clear that the refusal is essentially a refusal to give up what one takes to be one's own interest. The future is regarded not in terms of an unremitting series of deaths and births, but as though one's present system of ideals, virtues, goals, and advantages were to be fixed and made secure. ([4], p. 55).

In the above example from TAL, we presume that Refusal of the Call would actually be to remain in the STEM major - not to leave it - assuming this student's true calling is to foreign languages. Campbell's analysis has the hero paying attention to an uncovering of one's true interests, and therefore enacting only an apparent change in interest. To refuse the call is to persist unproductively with a false concept.

\section{Assistance from others}

When external influences support an intrinsic interest, the whole student is supported and more likely to persist. Often this is the result of good and encouraging high school teachers. TAL notes, "For students whose passion for mathematics and science is kindled at this flame, then focused and refined by Socratic dialogue, the influence of good teachers continues as a source of support and strength through times of academic difficulty." ([8], p. 61)

One female white science "non-switcher" says:

I think two reasons why I kept going in physics is because I had brilliant physics and chemistry teachers in high school-just excellent. That really kept me going. We had much more interaction and participation in class time, even in larger classes. ([8], p. 61)

This finding shares character with the Supernatural Aid theme, as "helpers" are deemed characters whose aid is what assists in the persistence through difficult times, or mythologically speaking, during The Road of Trials (see Sec. III.F). Campbell reflects in Pathways to Bliss [13]:

Once you have crossed the threshold, if it is really your adventure-if it is a journey that is appropriate to your deep spiritual need or readiness-helpers will come along the way to provide magical aid"..."letting you know what the dangers are along the way and how to overcome them." ([13], p. 116)

Not having the aid of helpers can make various challenges, especially academic ones, difficult to navigate: "Serendipity also played a part in persistence, often in the form of intervention by faculty at a critical point in the student's academic or personal life." ([8], p. 30)

\section{First-year experiences}

TAL describes difficulties faced by "gifted" students who found high school easy but the workload of college overwhelming: "I breezed through with high school very easily with high grades. I think a lot of kids that did well in high school are gonna come in and use the same study habits and get blown away. That's what happened to me." ([8], p. 84). Students also have emotional difficulties when facing a novel environment: "...I came here and failed my first exam. I'd never failed a test my whole life. I'd never failed anything. I went home and cried-over a stupid test!" ([8], p. 87)

These experiences map mythologically to The Crossing of the First Threshold:

With the personifications of his [sic] destiny to guide and aid him, the hero goes forward in his adventure until he comes to the "threshold guardian" at the entrance to the zone of magnified power. ...Beyond them is darkness, the unknown, and danger; just as beyond the parental watch is danger to the infant and beyond the protection of his society danger to the member of the tribe. ([4], p. 71). 


\section{E. Significant under-preparation}

TAL describes how under-preparation can lead to a downward spiral of disappointment with low-grades, decreased self-esteem, and the "ego-shock" of redefining themselves as incompetent. A female white engineering switcher says, "Anybody who's smart enough can muddle through anything. But when you get failing grades, and you're getting depressed, you lose interest. Once you stop going to classes, that tends to get you outta there fast."' ([8], p. 114)

These experiences are imaged mythologically as The Belly of the Whale, where "the hero, instead of conquering or conciliating the power of the threshold, is swallowed into the unknown, and would appear to have died." ([4], p. 83)

\section{F. Competence in a challenging field}

The Ultimate Boon is a stage in the HJ of peak experience characterized by effortlessness, transcendence of self, and participation in eternity. The hero "wins", but the reward is more profound than initially assumed. Campbell says, "Where the usual hero would face a test, the elect encounters no delaying obstacle and makes no mistake."([4], p. 160).

TAL offers no such corresponding experience, as it focuses on negative experiences. However, we recognized a connection to the contemporary concept of "flow", a condition of high challenges and skills, from empirical psychology. Flow can be achieved in any activity when it is pursued with clear goals, immersion, high attention, and a dedication to the present moment ([14], p. 209). A person in flow loses selfconsciousness (p. 62), experiences a transformation of time (p. 66), stretches their skills ([9], p. 816), and experiences a higher quality of life, even while working (p. 821). Flow has begun to be examined in PER as a measure of student positive experience during laboratory [15]. Because flow is so wellstudied as a psychological phenomenon, and its prerequisite conditions so well-understood, we believe that over time we will develop the ability to coach students effectively at identifying and stimulating flow experiences for themselves. These peak experiences can be framed as a great internal reward for their long-term disciplined engagement in physics. We believe when supporting students' reflections on their experiences that it will be important to support them in observing, designing, and sharing positive physics experiences.

\section{G. Post-graduation experiences}

After the boon, the hero is transformed and returns to their original society, perhaps struggling to re-integrate as a "master of the two worlds" ([4], p. 212). $70 \%$ of physics graduates nationally do not enroll in physics graduate programs ([16], p. 13), and so "return" to the non-academic world. These graduates who return to work are prized for their newly cultivated exceptional abilities, including "intellect... flexibility, persistence, and a high tolerance for accepting and overcoming initial failure." (p. 9) Discussion sessions should therefore engage physics students in reflection to prepare for this transition.

\section{POSSIBLE FORMAT OF DISCUSSION SESSIONS}

We currently intend to launch pilot sessions by inviting $\sim 5$ 8 self-selected students to an extra-curricular weekly discussion group, with each week themed according to a stage of the HJ. For example, taking The Belly of the Whale, the theme could be introduced with an open question about their own experience, such as "Have you ever felt totally lost and desperate in relation to your coursework?". After some quiet reflection, and inviting students to share their own experiences a bit, we might offer quotations from TAL, share a brief story that mythologically presents the belly of the whale theme, and explain how the stage figures in to the $\mathrm{HJ}$ as a whole. Finally, we would invite students to explain what connections they find between their own experience and those of others, from real history (TAL) and from myth (HJ), emphasizing a "growth mindset" [1] and persistent re-engagement with their physics studies.

\section{CONCLUSION}

Physics is a challenging field of study, and pursuing an undergraduate degree in it includes the additional metachallenge for students of orienting initially to its specific challenges. For many students, earning their UG degree will be the greatest accomplishment of their lives thus far. The hero's journey mythologically analyzes stages of a youngadult part of life that is oriented toward achievement, independence, and transformation; it appears to be promising as a positive growth-oriented framework for helping students interpret various experiences that they typically encounter in a UG physics program, especially adverse ones. We developed a correspondence between stages in the $\mathrm{HJ}$ and major themes in UG STEM experience, supplementing with the idea of "flow" from positive psychology. This correspondence forms the basis for developing future discussion protocols for extracurricular, mentor-led, inclusive student groups for encouragement, motivation, and moral support.

\section{ACKNOWLEDGMENTS}

This work is supported by NSF DUE 1557405. 
[1] C. S. Dweck, Motivational Processes Affecting Learning, American Psychologist 10.1037/0003-066X.41.10.1040 (1986).

[2] President's Council of Advisors on Science and Technology, Engage to Excel: Produce One Million Additional College Graduates with Degrees in Science, Technology, Engineering, and Mathematics, Tech. Rep. (2012).

[3] American Institute of Physics, Percent of Bachelor's Degrees Earned by Women in Selected Fields, Classes of 1981 through 2016.

[4] J. Campbell, The Hero with a Thousand Faces, comm. 2004 ed. (Princeton University Press, Princeton, NJ, 1949).

[5] C. G. Jung, Man and His Symbols, edited by C. G. Jung, M.-L. von Franz, J. L. Henderson, J. Jacobi, and A. Jaffé (Doubleday \& Company, Inc., Garden City, N.Y., 1964) p. 320.

[6] M. Murdock, The Heroine's Journey (1990).

[7] N. W. Brickhouse, Embodying science: A feminist perspective on learning (2001).

[8] E. Seymourand N. M. Hewitt, Talking About Leaving: Why Undergraduates Leave the Sciences (Boulder, CO, 1997) p. 429.

[9] M. Csikszentmihalyiand J. LeFevre, Optimal Experience in Work and Leisure, Journal of Personality and Social Psychology 10.1037/0022-3514.56.5.815 (1989).
[10] L. L. Espinosa, Pipelines and pathways: Women of color in undergraduate stem majors and the college experiences that contribute to persistence, Harvard Educational Review 81, 209 (2011).

[11] R. T. Palmer, D. C. Maramba, T. Elon, and D. Ii, Journal of Negro Education A Qualitative Investigation of Factors Promoting the Retention and Persistence of Students of Color in STEM, Source: The Journal of Negro Education Journal of Negro Education 80, 491 (2011).

[12] Z. Hazari, G. Sonnert, P. M. Sadler, and M.-C. Shanahan, Connecting high school physics experiences, outcome expectations, physics identity, and physics career choice: A gender study, Journal of Research in Science Teaching 47, n/a (2010).

[13] J. Campbell, Pathways to Bliss: Mythology and Personal Transformation, edited by D. Kudler (New World Library, Novato, CA, 2004) p. 224.

[14] M. Csikszentmihalyi, Flow: The Psychology of Optimal Experience (1990).

[15] A. Karelina, Designing a lab course from the perspective of flow theory (2015).

[16] Joint Task Force on Undergraduate Physics Programs, Phys21: Preparing Physics Students for 21st-Century Careers, Tech. Rep. (2016). 